\section{FRI0050 PATIENTS WITH RHEUMATOID ARTHRITIS ON METHOTREXATE. CASES OF APLASTIC ANAEMIA. FOLLOW UP OF FOURTEEN YEARS}

${ }^{1} \mathrm{P}$ Athanassiou, ${ }^{1} \mathrm{C}$ Antoniades, ${ }^{1} \mathrm{~A}$ Elezoglou, ${ }^{2}$ I Kostoglou-Athanassiou, ${ }^{1} \mathrm{G}$ Papadimitriou, ${ }^{1}$ A Boubougianni, ${ }^{1}$ A Akkizidou, ${ }^{1} G$ Vezyroglou. ${ }^{1}$ Department of Rheumatology, Asklepieion Hospital, Voula, Athens; ${ }^{2}$ Department of Endocrinology, Metaxa Hospital, Pireaus, Greece

\subsection{6/annrheumdis-2001.1179}

Background Methotrexate has been recognised as one of the main therapeutic agents used in rheumatoid arthritis (RA). However some of the adverse effects of low-dose methotrexate therapy and in particular pancytopenia have caused major concern.

Objectives The aim was to describe our experience of long-term follow up of patients with RA treated with low-dose methotrexate, in particular in reference to the appearance of pancytopenia. Methods During the last 14 years 528 RA patients were treated with methotrexate $7.5-15 \mathrm{mg} /$ week by the Rheumatology Department. These patients were followed up by the Rheumatology Department and they had a complete laboratory evaluation and clinical examination in regular intervals.

Results In 528 RA patients treated with low-dose methotrexate therapy over a period of 14 years 4 cases of aplastic anaemia were diagnosed $(0.76 \%)$. In these patients the white cell count, platelet count, haemoglobin and haematocrit values decreased. In all 4 cases liver function tests were slightly elevated. Folinic calcium was administered and white cell and platelet counts improved, while haematocrit remained stable. The increase in white cell count after the administration of folinic calcium was satisfactory and the addition of growth factors to aid haemopoiesis was not considered necessary. In a female patient a very marked decrease in white cell count was observed and the patient died from sepsis, despite the administration of antibiotics.

Conclusion Low-dose methotrexate therapy in long term followup appears to be a safe and effective form of therapy for RA patients. Therapy appears to be well tolerated by the patients. Pancytopenia appears to be one of the most significant and dangerous complications of this form of therapy, being observed even in the absence of other recognised risk factors. Pancytopenia may occur abruptly in patients with RA on low-dose methotrexate therapy. Regular laboratory investigations are essential for the early detection of this complication. The administration of supplement folate in patients with RA on low-dose methotrexate therapy may reduce the incidence of pancytopenia.

\section{FRI0051 DECREASE OF DISEASE ACTIVITY AND DISABILITY AND IMPROVEMENT OF QUALITY OF LIFE IN PATIENTS WITH REFRACTORY LONG-STANDING RHEUMATOID ARTHRITIS TREATED WITH MONOCLONAL ANTI- TUMOUR NECROSIS FACTOR-ALPHA ANTIBODY}

F Fantini, L Sinigaglia, S Zeni, M Cagnoli, P Colombelli, E Favalli, C Arnoldi, A Soldi. Reumatology, G. Pini Institute Milan, Milan, Italy

\subsection{6/annrheumdis-2001.1180}

Background Anti-tumour necrosis factor-alpha; (TNF-alpha) antibody has been recently introduced for the treatment of Rheumatoid Arthritis (RA).

Objectives To evaluate the efficacy of anti-tumour necrosis factor-alpha (TNF-alpha) antibody associated with low-dose methotrexate (MTX) on disease activity, disability and quality of life in a group of RA patients non responder to traditional DMARDs.
Methods Forty-five non responder patients (42 F, 3 M; age 52 \pm 11.7 ) with long-standing refractory active (DAS28 $>4$ ) rheumatoid arthritis (disease duration $15.5 \pm 8.8$ years) were included in an open study. Before entry most of the patients were on a combination DMARDs regimen. Patients were treated with slow i.v. infusions (at day 0, 15, 45 and then every 45 days) with monoclonal anti-TNF-alpha antibody (Infliximab, 3 $\mathrm{mg} / \mathrm{Kg}$ ) associated with low-dose weekly MTX (median dose 13 $\mathrm{mg}$ ). Symptomatic treatment was stable during the observation. At every control the following parameters were evaluated: number of tender and swollen joints, pain VAS, General Health assessment VAS (GH VAS), ESR, CRP, haemoglobin level, DAS index, Health Assessment Questionnaire (HAQ), Short Form 36 (SF-36). Until now 37 patients completed a 6 months (6 infusions) whereas 11 patients completed a 12 months (10 infusions) course of treatment.

Results After 45 days a statistically significant improvement of all the parameters with the exception of CRP and haemoglobin level was observed. The long-term observation, up to month 6 (37 pts) and month 12 (11 pts), showed a statistically significant decrease of DAS, number of tender joints and pain VAS. The same statistically significant trend was observed also for parameters related to quality of life. The infusion was generally well tolerated. Major side effects leading to drug withdrawal were registered in 6 patients (hiperpyrexia in 2 patients, allergic reactions in 3 patients and pulmonary tuberculosis in 1 patient).

\begin{tabular}{|c|c|c|c|c|}
\hline & $\begin{array}{l}\text { Basal } \\
\text { T0 (45 } \\
\text { pts) }\end{array}$ & $\begin{array}{l}\text { After } 2 \\
\text { infusions } \\
\text { Day } 45 \text { (45 pts) }\end{array}$ & $\begin{array}{l}\text { After } 5 \\
\text { infusions } \\
\text { Month } 6 \text { (37 } \\
\text { pts) }\end{array}$ & $\begin{array}{l}\text { After } 9 \text { infusions } \\
\text { Month } 12 \text { (11 } \\
\text { pts) }\end{array}$ \\
\hline DAS & 5.96 & $4.62^{*}$ & $4.7^{*}$ & $4.64^{*}$ \\
\hline HAQ & 2.13 & $1.73^{*}$ & $1.78^{*}$ & $1.65^{*}$ \\
\hline $\begin{array}{l}\text { Physical DIM SF- } \\
36\end{array}$ & 18.8 & $39.3^{*}$ & $39.68^{*}$ & $39.36^{*}$ \\
\hline $\begin{array}{l}\text { Mental DIM SF- } \\
36\end{array}$ & 36.5 & $59^{*}$ & $52.19^{*}$ & $56.18^{*}$ \\
\hline
\end{tabular}

Conclusion Monoclonal anti-TNF-alpha antibody in association with MTX induced a prompt and long-lasting (at least one year) symptomatic response with a significant decrease of disease activity and disability and an improvement of quality of life in a series of patients with rheumatoid arthritis refractory to traditional DMARDs.

\section{FRI0052 TO EVALUATE ANTIBODIES ANTINUCLEAR (ANA) IN RHEUMATOID ARTHRITIS WITH INFLIXIMAB TREATMENTOID}

${ }^{1} \mathrm{~F}$ Gamero- Ruiz, ${ }^{1} \mathrm{G}$ Bonilla, ${ }^{1} \mathrm{G}$ Diaz, ${ }^{2} \mathrm{JM}$ Gonzalez-Tarrio, ${ }^{2} \mathrm{R}$ Alvarez-Doforno, ${ }^{1} \mathrm{~A}$ Balsa, ${ }^{1}$ E Martin-Mola. ${ }^{1}$ Rheumatology; ${ }^{2}$ Inmunology Service, Hospital La Paz, Madrid, Spain

\subsection{6/annrheumdis-2001.1181}

\section{Background}

Objectives To examine the evolution of the ANA titre in patients with rheumatoid arthritis treated with infliximab (anti TNFalpha). 
Methods 14 patients with active rheumatoid arthritis and unresponsive to at least 3 DMARDs were treated with methotrexate and infliximab. Before infliximab infusion, weeks 0, 2,6,14 and 22, a physical examination, DAS 28 and blood test, which included RF, ANA, immunoglobulin quantification C3 and C4 were done.

Results At the baseline visit 5/14 (35,71\%) patients had positive ANA test,2 (1/40), 1 (1/80), 1 (1/160), 1 (1/640). After the fifth infusion $8 / 14(57,14 \%)$ had a positive ANA test. Three patients who initially were ANA negative showed a titre of $1 / 160,1 / 320$ and $1 / 640$. Three out of 5 patients which previously had a positive test, showed an increase in the ANA titre, $1 / 40$ to $1 / 80,1 / 40$ to $1 / 320$ and $1 / 640$ to $1 / 1280$. After the fourth infusion of infliximab, all patients with ANA positive had a Crithidia test performed. In all cases anti DNA were negative.

Conclusion In our experience, treatment with infliximab has shown an increase of the ANA titre in $21,42 \%$ of the patients. On the other hand, $21,4 \%$ of the patients with a previous negative test for ANA had a positive test after the fourth infusion. All cases were negative for anti-DNA antibodies.

\section{FRI0053 STEROIDS RESTORE THE IMPAIRED CERULOPLAMIN FERROXIDASE ACTIVITY IN SYNOVIAL FLUID OF RHEUMATOID ARTHRITIS}

V Livshitz, AM Nahir. Rheumatology, Faculty of Medicine - Technion, Haifa, Israel

\subsection{6/annrheumdis-2001.1182}

Background Ceruloplasmin (CP) is an acute phase reactant with significant antioxidative activity. In rheumatoid arthritis (RA), joint destruction continues in spite of high levels of CP in the synovial fluid (SF). The antioxidative activity of CP correlates with its ferroxidase I activity (FerrI). The biology role of the recently discovered ferroxidase II (FerrII) is unknown.

Objectives The present study was aimed to find the effect of drug therapy on CP levels and CP ferroxidase activity in RA SF and to compare it to SF nitrite levels, which indicate the degree of the inflammatory process.

Methods SF was collected from 75 RA patients who were:

- w/o drug therapy (UT).

- with NSAIDs and disease modifying drugs (DMD), mainly MTX who had no steroid in the last 3 months (NST).

- with low dose steroids $(=/<10 \mathrm{mg}$ Prednisone $)+$ DMD ST).

- SF of osteoarthritic (OA) patients served as control. For CP levels Ravin's method was used. ${ }^{1}$ For CP ferroxidase activity Johnson's method was used. ${ }^{2}$ For FerrII activity Johnson's method in the presence of sodium azide. FerrI activity was calculated: Total-FerrII. For nitrite levels Ding's method was used. ${ }^{3}$

Results Inspite of drug therapy and nitrite level similar to OA, $\mathrm{CP}$ and total ferroxidase activity remained high in all RA groups. FerrI/FerrII ratio was significantly abnrmal in RA without steroids. Low dose steroids restored FerrI/FerrII ratio to levels seen in OA.

Conclusion Low dose steroid therapy in RA did not reduce SF ceruloplasmin concentration, but restored FerrI/FerrII ratio to normal levels.

\section{REFERENCES}

1 Ravin HA. J Lab Clin Med. 1961;58:161-8

2 Johnson DA, et al. Clin Chem. 1967;13:142-9

3 Ding $\mathrm{AH}$, et al. J Immunol. 1998;141:2407-13
FRI0054 A LONG-TERM, OPEN-LABEL TRIAL OF THE SAFETY AND EFFICACY OF ETANERCEPT (25 MG TWICE WEEKLY) IN PATIENTS WITH RHEUMATOID ARTHRITIS (INTERIM ANALYSIS)

RF Willis, R Pedersen. The Etanercept European Investigators Network, Wyeth-Ayerst Research, Radnor, USA

10.1136/annrheumdis-2001.1183

Background Several double-blind, placebo-controlled studies previously demonstrated that etanercept was safe and efficacious in treating rheumatoid arthritis (RA) patients who had an inadequate response to disease-modifying antirheumatic drugs (DMARDs).

Objectives To evaluate the long-term safety and efficacy of etanercept in patients who completed prior double-blind clinical studies comparing etanercept to placebo.

Methods As reported in previous updates, 549 patients entered this 4-year, open-label study and began treatment with etanercept $25 \mathrm{mg}$ twice weekly at 58 centres in Europe following completion of double-blind clinical studies. All patients previously had inadequate responses to DMARDs. Safety assessments were performed at regular intervals to determine the incidence of treatment emergent adverse events including malignancies and serious infections (those associated with hospitalisation and/or the administration of intravenous antibiotics). The numbers of painful and swollen joints were predefined as primary efficacy endpoints; other efficacy measures included ACR response rates and acute phase reactants. Efficacy was analysed with the last observation carried forward (LOCF).

Results Of the 549 patients initially enrolled, 437 (80\%) are currently active, 479 (87\%) completed 1 year, and 94 (17\%) completed 2 years. A total exposure of 927 patient-years has been accrued. The rate of withdrawal from the study was similar for efficacy- and tolerance-related reasons $(7 \%$ and $8 \%$, respectively). Adjusted for patient exposure, the most frequent adverse events were injection site reactions and upper respiratory infections. Rates of serious infections and malignancies have remained unchanged over the course of the study. Maintained efficacy was observed as demonstrated by a mean $71 \%$ and $72 \%$ reduction in painful and swollen joint counts, respectively. Similar to results measured at the early time points of this open-label trial, ACR 20,50 , and 70 response rates were determined to be $79 \%, 47 \%$, and $25 \%$, respectively, as patients approached two years of treatment.

Conclusion Following the accumulation of substantial exposure in patients with RA, etanercept demonstrates an acceptable safety profile and continues to provide significant and maintained clinical benefit.

\section{FRI0055 EXPERIENCE WITH COMMERCIAL REMICADE (INFLIXIMAB) AT A LARGE COMMUNITY-BASED RHEUMATOLOGY PRACTICE}

W Shergy, RM Phillips, RE Hunt, J Hernandez. Associate Clinical Professors of Medicine, University of Alabama/Huntsville and Rheumatology Associates of N. Alabama, Huntsville, USA

\subsection{6/annrheumdis-2001.1184}

Background Infliximab, a monoclonal antibody that binds with high affinity and specificity to TNF-alpha and neutralises its biologic activity, is approved for the reduction of the signs and symptoms of rheumatoid arthritis (RA). The Rheumatology 